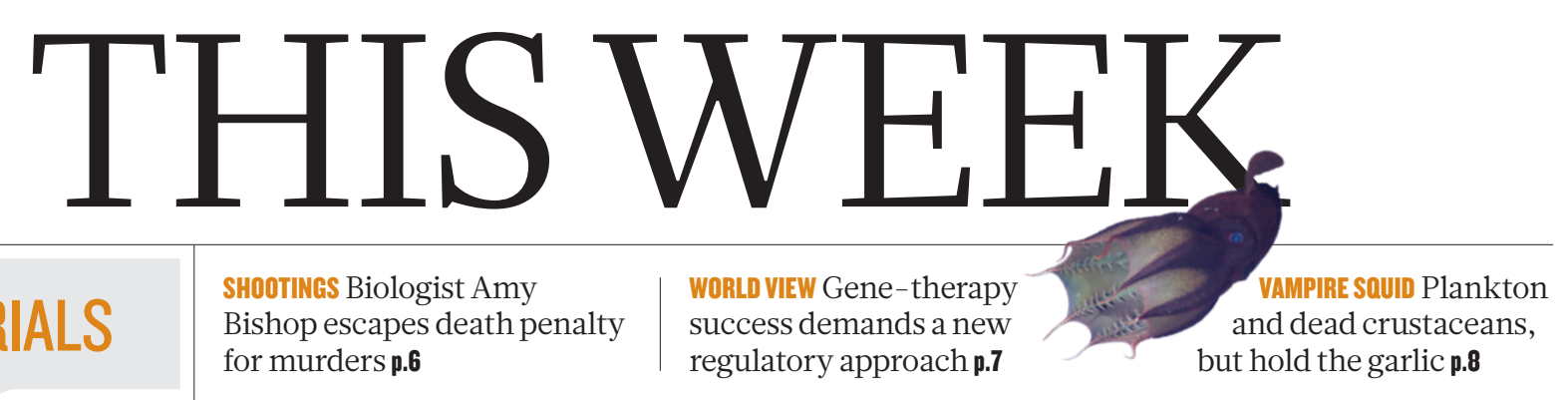

\section{EDITORIALS}

WORLD VILW Gene-therapy regulatory approach $\mathbf{p . 7}$

\title{
The price of progress
}

\section{A new uranium enrichment technique approved by the US Nuclear Regulatory Commission could have an impact on nuclear proliferation. This should have been taken into account.}

$\mathrm{S}$ cientists and scientific journals are naturally inclined towards progress. But there are exceptions: progress is not always better. Last week, the US Nuclear Regulatory Commission (NRC) in Rockville, Maryland, announced that it had issued a licence for a new technology to enrich uranium using lasers - a process that is potentially cheaper and better than current enrichment methods, but also politically fraught and possibly dangerous (see Nature http://doi.org/ jfr; 2012). The decision was unfortunate. The NRC should introduce rules to ensure that its future moves are better informed.

Nuclear power and nuclear weapons both require uranium that has been enriched to contain higher levels of uranium-235 than occurs naturally. The 1970 nuclear non-proliferation treaty gives countries the right to possess enrichment systems, but most are subject to strict controls. Where facilities are declared as peaceful, they are subject to inspection by the International Atomic Energy Agency, which ensures that material is not diverted for military or criminal purposes. National intelligence agencies, too, keep a careful eye on the activities of friends and rivals worldwide.

Current techniques to separate uranium-235 from its heavier, nonfissile sibling uranium-238 are hard to hide. They typically involve enormous gaseous-diffusion plants, or smaller, energy-intensive centrifuge facilities that spin the two isotopes apart in high-speed machines. Both require lots of space and electricity, which means that such facilities are easy to spot with, say, satellite reconnaissance.

Lasers are more discreet. When finely tuned, they can ionize uranium-235 that can then be collected on a negatively charged plate. The new technique will require considerably less space and electricity than centrifuge or diffusion plants.

GE Hitachi, the multinational company pursuing laser enrichment, describes it as a "game-changing technology", and those who fear nuclear proliferation agree. Understanding where enrichment facilities are and how they operate is crucial to maintaining the treaties and agreements that limit the spread of nuclear technology. When undeclared enrichment facilities are uncovered, as happened in Iran in 2009, it can spark an international crisis. Even more worrying is the possibility that some facilities can simply never be detected. Mistrust could lead to regional arms races and even open conflicts.

When the NRC approved GE Hitachi's application for a laser enrichment plant, it considered physical security, such as the height of the fence around the plant. But the commission did not explicitly address the existential threat that a plant might pose to the non-proliferation regime, nor did it concern itself with the message that the pursuit of this technology might send to other nuclear nations.

The American Physical Society (APS), based in College Park, Maryland, would like to change that. Backed by environment groups and scientists, the society has proposed that the NRC change its regulations to require future applicants to submit a 'proliferation review'. This would force the commission and corporations to consider the

proliferation consequences of their proposed facilities. It would also provide a public focus for debate, much as environmental-impact statements have allowed activists and citizens to query the environmental aspects of construction.

Could such a review have changed the outcome of the NRC's licence decision? Perhaps. From a commercial standpoint, the benefit of laser enrichment is clear, but from a broader societal perspective, it is questionable. The cost of fuel for nuclear reactors is dwarfed by the cost

"To consider proliferation might seem beyond the remit of a regulator, but it is not." of construction, and this has stalled a nuclear renaissance in the West. A 2010 analysis showed that the savings to households would be less than US\$10 per year from laser enrichment - a saving that many homeowners might be unwilling to accept if presented with the risks the technology poses (see F. Slakey and L. R. Cohen Nature 464, 32-33; 2010).

The APS's proposed rule change will be voted on by the five NRC commissioners in November. Nature urges the commissioners (who were not directly involved in approving the laser enrichment system) to approve the change. To consider something as vague as proliferation might seem beyond the remit of a regulator, but it is not. Under the Atomic Energy Act of 1954, the NRC is charged with considering whether its licences would "be inimical to the common defense and security" of the US public. Nuclear technologies that are potentially destabilizing pose a threat to the security of citizens everywhere, and so the commission could rightly consider it under an altered licensing process. In the case of laser enrichment, as with other technologies, progress should be judged on more than the technical merits alone.

\section{Power cuts}

\section{China's slumping renewable-energy industry should be learnt from, not dismissed.}

$\mathrm{T}$ hese are testing times for the renewable-energy boom in China. On 3 August, the head of a Chinese solar-energy company leapt to his death because his firm couldn't pay off a loan. Last month, LDK Solar in Xinyu City cut its earnings forecast for the second consecutive time, and watched its stock drop to one-quarter of what it was a year ago after it defaulted on payments. Suntech Power in Wuxi, the world's biggest producer of solar panels, announced plans to slash production and was forced to accept a loan worth US $\$ 32$ million from the local government to stay afloat. China's wind-turbine manufacturers are also being forced to watch sales drop in an overcapacity market. 